Session ETD-345

\title{
Increase Student Capacity with Effective K-12 Outreach
}

\author{
Ann Laird \\ Learning and Academic Affairs Department \\ Mohawk Valley Community College \\ Utica, New York
}

\begin{abstract}
Successfully building the student pipeline for engineering tech programs requires a multi-prong approach. Increasing awareness of programs is critical to expand the pipeline, and this can be done through sustained-period outreach efforts, bringing secondary students to the college campus; one-time (repeatable) outreach efforts; sustained-period outreach at secondary schools; providing middle and secondary teacher professional development opportunities; creating beneficial outreach partnerships; and providing the right information to parents of potential future students.

Case studies of successful outreach performed through NSF-funded projects at community colleges on both the east and west coasts are presented in this paper.
\end{abstract}

\section{Introduction}

As in many technical career sectors, thousands of engineering and engineering technology jobs go unfilled as the pool of candidates remains low. Industry knows this all too well, and the message is reaching the public. Of the 2,000 Americans who were surveyed in a 2018 Emerson survey [1], 40\% acknowledge a STEM worker crisis and nearly half reported they expect the number of STEM jobs will grow in the U.S. in the next ten years, yet more than $50 \%$ of the respondents reported that their daughters are not encouraged to pursue STEM careers.

The National Science Foundation (NSF) encourages active recruiting of underrepresented populations for technical education to increase and diversify workforce pipeline growth. NSF support in this area should translate to increasing the encouragement young women feel to pursue technical education.

Effectively promoting an awareness of engineering and engineering technology education programs will lead to gains in the student pipeline. Increased awareness must be targeted to more than potential students alone. Secondary school teachers, secondary school counselors, college recruiters, and parents of prospective students are all in need of targeted exposure to increase awareness and change any potential misperceptions. Case studies on adaptable methods for outreach are offered for consideration below.

\section{Sustained Period on College Campus}

STEM outreach over time on the college campus gives secondary and middle school students an experience of being a student on a college campus. This familiarity is an important step in making students feel comfortable with the idea of continuing their education at a specific 
institution. Instructors for these outreach programs must be youth-friendly and very enthusiastic about the learning the students will embark on.

The conversion rate on this type of outreach at the college is not yet quantifiable as the student population is still attending middle or secondary school. The first attempt with this outreach under the NSF project was completed recently with a group of 8th and 9th graders from a local science charter school (Group A). A continuing effort is in session as this paper is written with groups of 9th, 10th, and 11th graders at another local high school (Group B). Group B began three years ago with a 9th grade cohort learning about drone technology. In the second year, the college added robotics sessions for the previous 9th grade cohort and began a new cohort of 9th graders learning about drones. In this third year, the college added GIS mapping/tree identification curriculum for the now 11th grade cohort of original students. All of these students belong to the under-represented populations that are necessary to successfully build the education pipeline to employment in technical careers.

These two outreach examples take place once a week over eight weeks. Group A students were on campus for one and a half hours each week, as that was the amount of time the charter school allowed for. Group B students were on campus for three hours each week and a meal was provided through a community partner, who solicited meals from local restaurants. Two to three hours a week is ideal. A digital portfolio was created for the students, with sentence stems for each week. Students were given time at the end of each session to reflect on their learning in their portfolios.

A new sustained period outreach will be performed over the summer: partnering with the Upward Bound program. More information on this outreach can be found in the Partners section of this paper.

\section{Sustained Period on High School Campus}

Consider co-locating a career coach in area high schools and vocational technical schools. In three years' time, the career coach working on a NSF manufacturing education project had regular hours in career centers at six area high schools and one technical skills center that serves 44 high schools in the region. Her efforts provided 2,095 students with tours of the community college's education facility and the local aerospace manufacturing industry. She provided 941 classroom presentations, visited with 1,346 students in high school career centers, and reached 3,088 students through various career events.

One way to market to the students via outreach is to plan workshops, tours, information sessions, etc. for student career exploration. As an example, the career coach mentioned above created a program she named "SNAP4\$UCCESS" and created a handout to explain the program to students. The flyer included information about four steps she planned for student success. Step 1: workshop and discussion around local job titles that fall within the high wage/high demand category; Step 2: a field trip to the school's advanced manufacturing technical education center and local manufacturers; Step 3: we partnered with AJAC (a nonprofit aerospace and advanced manufacturing registered apprenticeship program) to bring their mobile training unit (MTU), a 53-foot classroom on wheels, to high school campuses where students could tour the MTU and learn through hands-on exercises in the MTU; and Step 4: a VIP information session providing assistance with summer and fall college course registration. 
During the final year of the grant, we assisted and coached 200 students through the college application and registration processes. The efforts of the career coach established new registration processes for high school students as a resolution to three major barriers she discovered while working with them: financial aid, placement testing, and entry advising. Working directly with the financial aid director, she was able to mitigate many financial aid issues for students. Her efforts were the impetus for campus-wide change in placement testing for recent high school graduates; using high school transcripts for placement, alleviating the stress of another test. Finally, there were often long waiting times for entry advising, meaning sometimes students did not register for classes in the semester they planned to. The career coach worked to bring college-entry advisors to the high schools to advise in a group setting and removed what was a huge barrier for students.

\section{One Time (Repeatable) Outreach}

Design and offer spatial awareness workshops. In researching reasons why the number of females in engineering and engineering technology careers remains low, the work of Sheryl Sorby, PhD, was enlightening. A workshop based on highlighting one of the largest gender differences in cognitive abilities in the area of spatial skills was created and is delivered to middle and high school girls so they have the information and can gauge their spatial intelligence. If they find it lacking, practical ways to develop spatial skills are introduced in the workshop. The growth mindset and the different types of multiple intelligences are also introduced. The workshop ends with girls testing their spatial abilities through flying drones.

Participate or create Manufacturing Day events. Promote tours of your educational facility on Manufacturing Day. This can be coordinated with local middle and high schools to bus students for a tour of a higher education experience that they may not yet be aware of or coordinating separate tours of local industry facilities for subsets of CTE students with particular interests.

Host a high school guidance counselor tour of your educational facility. They may know OF facilities, but a stronger connection is made when they can SEE them and talk with educators about different options for students. This connection is an important one.

Host a Girls STEM Expo or an Engineering Design Competition for middle and/or high school girls on the college campus. Exposure to your campus and the many possibilities available in STEM education can be a wonderful eye-opener for undecided youth.

\section{Teacher Professional Development}

Providing a space for middle and high school teachers to develop relationships with one another and the college faculty is an effective method to increase networking and collaboration. Following are case studies of three faculty institutes that were offered during a NSF project in advanced manufacturing education. Year one helped to create strong bonds with local high school CTE teachers and CTE director. Year two brought together these CTE teachers and CTE, math, and science teachers from 14 area schools, and year three brought together relatively new STEM teachers from 13 schools around the state, led by the CTE teachers we worked with in year one. The final year's PD activities modeled the desired connection of secondary and postsecondary educators and led teachers from outside the immediate region to look into how they could connect with their local community colleges in a similar way. 


\section{Year One}

Working with a local high school's CTE teachers and the district CTE director, we were able to facilitate a paradigm shift in the high school manufacturing CTE program, creating a framework that was approved for statewide adoption. A project-based learning (PBL) course was developed that allowed students to identify and understand the complete design and manufacturing process while learning the key values of project management and 21st century skills involving group dynamics and teamwork.

Year Two

A 4-day professional development PBL workshop was designed for local high school and middle school CTE, science and math teachers. The workshop was led by community college faculty who investigated math, science, and manufacturing concepts with the secondary teachers who learned how to fabricate parts for a Stirling engine fan. The teachers worked in a collaborative learning environment and took the fans back to their classrooms and proudly showed off, "I made this!" The teachers remained in contact and shared curriculum revisions with one another, turning in a culminating report on their workshop experience and their plans for PBL adaptation in the classroom.

\section{Year 3}

A 4-day professional development workshop titled STEM Survival Solutions was presented to 14 teacher participants from around the state who were relatively new to CTE. The workshop was delivered by seasoned high school CTE teachers from the year 1 cohort who shared tips on classroom management and kit design. The teachers were exposed to reverse engineering purchased kits, then creating kit parts with Rhino CAD, laser cutters, water-jet cutting, 3D printers as prototyping opportunities for their students in the classroom. The discovery of math and science standards inherent in the project were documented. A Google drive was created for the teachers to share ideas with one another after the PD. A strong cohort of teachers who can connect with one another over time was one of many positive outcomes of this PD.

\section{Create Beneficial Outreach Partnerships}

As mentioned earlier in this paper, a new sustained summer outreach is being planned with a partner within the community college: Upward Bound (UB). UB is a US Department of Education program serving populations of under-represented high school students. The college department working with these students asked us to participate in a five-week program being offered this summer. Students will be on campus full days, four days a week for five weeks, experiencing different educational options. We will be working with up to 60 students in four cohorts of 15 for two hours each day, exploring and experiencing the educational requirements for a degree in remotely piloted aircraft systems. These high school students will be using our facilities and equipment and will engage with students and faculty in the program, allowing for a sense of comfort with this potential new avenue of study for them in the future.

Other partners within a school system were engaged in the NSF-funded advanced manufacturing project mentioned previously. These included Running Start students (high school students taking college classes on the college campus) and Youth Reengagement students (previous dropouts returning to school) where tours of the school's advanced manufacturing facility were provided and classroom presentations were delivered. 
Participation in the college's annual outreach events such as a Students of Color Career Conference, a one-day conference where high school students from several schools were bused to the college campus for a day of learning about programs and external events such as a county initiative named Build Your Future where students were bused to an off-campus location. and several colleges provided hands-on activities and information sessions on programs of interest.

Industry partners are an excellent resource for student tours. Providing opportunities for students to see possible places of their future employment is a highly experiential form of outreach. Employers really enjoy engaging with potential future employees and students get a realistic inside look at careers they are considering. Industry tours provide college faculty with opportunities to develop relationships with industry personnel which also benefits students.

Tours of your educational facility are a beneficial way to reach out to community partners, such as Big Brothers Big Sisters, Girl Scouts and Boy Scouts and other youth development programs, CTE directors from area high schools, local employers, middle school and elementary school classes, and high school STEM teachers.

\section{Provide the Right Information to Parents of Potential Future Students}

Columbus State Community College (CSCC) is given time during high school parent information nights to promote its technology programs. This has proven effective because there is a captive audience that needs to hear a message about post-high school options. CSCC works with the high school principal to promote technology programs at the community college. On stage is the high school principal, a college representative for technical programs (dean or president is recommended), a four-year college representative, and a high-ranking representative of a local technology business that recruits employees from the community college program graduates. These subject matter experts give the parents information about careers and incomes that are possible for their graduating seniors to consider regarding two- and four-year degrees. This is a highly effective approach.

\section{Summary}

This paper provides an overview of outreach programs that build student pipelines for engineering technology programs at community colleges. Building student pipelines and informing youth about education and career opportunities in engineering technology is necessary to meet current and future workforce development requirements.

\section{References}

[1] “Emerson Survey: 2 in 5 Americans Believe the STEM Worker Shortage is at Crisis Levels,” 2018. [Online]. Available: https://www.emerson.com/en-us/news/corporate/2018-stem-survey

\section{Biographical Information}

ANN LAIRD is coordinating a National Science Foundation (NSF) Advanced Technology Education (ATE) project in drone technology at Mohawk Valley Community College in Utica, NY, and previously directed a NSF-ATE 
Session ETD-345

project in Aerospace Advanced Manufacturing at Everett Community College in Everett, WA. Ann earned her BA in Business Administration from Alaska Pacific University in Anchorage, AK, and her MEd in Leadership from Concordia University in Portland, OR. 